\begin{tabular}{cc}
\hline Bentham open & $\begin{array}{c}\text { Clinical Practice \& Epidemiology in } \\
\text { CrossMark }\end{array}$ \\
Content list available at: www.benthamopen.com/CPEMH/ \\
DOI: $10.2174 / 1745017901713010255$
\end{tabular}

\title{
CORRIGENDUM
}

\section{Cognitive Dysfunction in Asian Patients with Depression (CogDAD):} A Cross-Sectional Study

Srisurapanont Manit ${ }^{1, *}$, Mok Yee Ming ${ }^{2}$, Yang Yen Kuang ${ }^{3}$, Chan Herng-Nieng ${ }^{4}$, Della Constantine $\mathrm{D}^{5}$, Zainal, Nor Zuraida ${ }^{6}$, Jambunathan Stephen ${ }^{7}$, Amir Nurmiati $^{7}$ and Kalita Pranab ${ }^{8}$

${ }^{I}$ Department of Psychiatry, Faculty of Medicine, Chiang Mai University, Chiang Mai, Thailand

${ }^{2}$ Institute of Mental Health, View, Buangkok Green Medical Park, Buangkok, Singapore

${ }^{3}$ Department of Psychiatry, National Cheng Kung University, Cheng Kung National University Hospital, Tainan, Taiwan,

${ }^{4}$ Department of Psychiatry, Singapore General Hospital, Academia, Singapore

${ }^{5}$ College of Medicine, University of the Philippines, Manila, Philippines

${ }^{6}$ University Malaya, Jalan Universiti, Kuala Lumpur, Wilayah Persekutuan, Malaysia

${ }^{7}$ Department of Psychiatry, Cipto Mangunkusumo Hospital, University of Indonesia, Jakarta Pusat, Indonesia

${ }^{8}$ Lundbeck Singapore Pte. Ltd., 101 Thomson Road, Singapore

The correct spelling of last author's name is provided and replaced online which is mentioned as under:

Srisurapanont Manit, Mok Yee Ming, Yang Yen Kuang, Chan Herng-Nieng, Della Constantine D, Zainal, Nor Zuraida, Jambunathan Stephen, Amir Nurmiati, Kalita Pranab

The wrong spelling was:

Srisurapanont Manit, Mok Yee Ming, Yang Yen Kuang, Chan Herng-Nieng, Della Constantine D, Zainal, Nor Zuraida, Jambunathan Stephen, Amir Nurmiati, Kalita Pranabi

\footnotetext{
* Address correspondence to this author at the Department of Psychiatry, Faculty of Medicine, Chiang Mai University, 110 Intavaroras Road, Muang, Chiang Mai, 50200, Thailand, Tel: +6653-94-5422-4, E-mail: manit.s@cmu.ac.th
}

\section{(C) 2017 Manit et al.}

This is an open access article distributed under the terms of the Creative Commons Attribution 4.0 International Public License (CC-BY 4.0), a copy of which is available at: https://creativecommons.org/licenses/by/4.0/legalcode. This license permits unrestricted use, distribution, and reproduction in any medium, provided the original author and source are credited. 